\title{
Residues Analysis of Acetamiprid, Boscalid, Imidacloprid and Pyraclostrobin in the Minor Crop Mustard Green under Greenhouse Conditions for Evaluation of their Potentiality of PLS Violation
}

\author{
Young Eun $\mathrm{Kim}^{\dagger}$, Seon Wook $\mathrm{Kim}^{\dagger}$, Da Jung Lim and In Seon Kim \\ Department of Agricultural Chemistry, Chonnam National University, Gwangju 61186, Korea
}

Received: 13 July 2020/ Revised: 27 July 2020/ Accepted: 26 August 2020

Copyright (C) 2020 The Korean Society of Environmental Agriculture

This is an Open-Access article distributed under the terms of the Creative Commons Attribution Non-Commercial License (http://creativecommons.org/licenses/by-nc/3.0) which permits unrestricted non-commercial use, distribution, and reproduction in any medium, provided the original work is properly cited. the matrix calibration curves of the pesticides showed linearity with coefficient values of determination $\left(\mathrm{r}^{2}\right)$ greater than 0.995 . The average recovery values of the pesticides fortified in control samples at rates of LOQ and 10LOQ ranged from approximately $77.5 \%$ to $101.2 \%$ with relative standard deviation values lower than $14 \%$. The pesticides in the mustard green samples cultivated for 53 days after sown were determined to be lower than the LOQ level.

CONCLUSION: Acetamiprid, boscalid, imidacloprid and pyraclostrobin were found at a level lower than $0.01 \mathrm{mg} / \mathrm{kg}$ in the minor crop mustard green. Thus, their residues in mustard green would not violate PLS under greenhouse conditions.

Key words: Acetamiprid, Boscalid, Imidacloprid, PLS, Pyraclostrobin

\section{Introduction}

Korea has established Positive List System (PLS) as a pesticide safety law for agricultural products in December 31, 2016 and has applied the system to crops including seed and nut products and tropical fruits, and now has enforced PLS to whole agricultural products since January 1,2019 . The number of anxious issues have arose from agricultural farmers who would receive financial 
penalty based on the violation of PLS due to unpredictable pesticide contamination of crops. The rotational crop system is a typical concern on the unpredictable pesticide contamination because the secondary crop would be contaminated with the pesticide that had been used for the first crop. In Korea, the rotational crop system has been largely performed for minor crops in greenhouses. Thus, much effort is required to allow for minor crops not to violate PLS.

Minor crops have been typically accepted as one of income crops for farmers because the crops could be harvested in a few month after seeding or transplanting. In Korea, minor crops named agricultural plants grown in overall cultivation area smaller than 1,000ha. According to Rural Development Administration (RDA) of Korea, the cultivation variety of minor crops has increased yearly, particularly in greenhouse system [1]. The need of pesticide registration for the control of plant pathogens and pest insects in minor crops are triggered by agricultural farmers in association with the variety. Thus, methods for the determination of pesticide residues in a program of pesticide registration are essentially required.

Determination of pesticides in crops is of important not only for protection of human health but also for regulatory control of agricultural foods. QuEChERs method has been currently introduced as a powerful tool for sample preparation in a program of pesticide residue analysis $[2,3]$. The method is based on reducing organic solvent use and sample preparation steps such as extraction, clean-up and concentration. QuEChERs methods have been well coordinated to mass spectrometry as multiresidue analytical methods for the determination of pesticides in agricultural food stuffs [4-6]. Acetamiprid, boscalid, imidacloprid and pyraclostrobin are one of pesticides widely used to control pest insects and plant pathogens in greenhouse [7-11]. According to National Agricultural Products Quality Management Service (NAQS), they are one of the major pesticides that have been detected in agricultural soil samples by yearly domestic pesticide monitoring program. NAQS has particularly interested in imidacloprid and acetamiprid because they were found in rotational minor crop such as perilla leaf. Giving the situation, acetamiprid, boscalid, imidacloprid and pyraclostrobin are now in a situation that Korean government should consider the registration for their use in rotational minor crops because agricultural food safety becomes an important issue due to their potentiality of unpredictable pesticide contamination against PLS law. Thus, much effort is required to examine these pesticide residues in rotational minor crop. In this study, we used modified QuEChERs methods coupled with LC/MS/MS to examine the residues of acetamiprid, boscalid, a pyraclostrobin metabolite BF 500-3, imidacloprid and pyraclostrobin in mustard green samples cultivated under greenhouse conditions. Based on the experimental data, we evaluated potential violation of the pesticides against PLS.

\section{Materials and Methods}

\section{Chemicals and Reagents}

Acetamiprid (purity 100\%), boscalid (purity 99.5\%), imidacloprid (purity 100\%), pyraclostrobin (purity 99.9\%), and a pyraclostrobin metabolite BF500-3 (purity 99.9\%) were purchased from Sigma-Aldrich Corporation (St Louis, MO, USA). Their chemical structures are presented in Fig. 1. All solvents were HPLC grade purchased from J.T. Baker Chemicals (Phillipsburg, NJ, USA). QuEChERs kits and SPE cartridge columns were obtained from Agilent Technolgies (CA, USA). All chemicals were reagent grade purchased from Fisher Chemical (PA, USA) and Junsei Chemical Co. Ltd (Tokyo, Japan), unless otherwise stated.

\section{Field Trials}

Field trials were performed at a greenhouse (Damyang, Jeonnanm) to investigate the residues of acetamiprid, boscalid, imidacloprid, pyraclostrobin and BF500-3 in the mustard green samples. The trials were conducted in the soil treated with the pesticides at a level highly exposable to the secondary crop. Pesticide granule formulation (GR) was chosen as a test formulation type because it was hypothesized to find the residue level at a level higher than other types in the soil after used in the first crop. Commercial GRs were mixed thoroughly with a small portion of soil at a ratio of 1 to $30(\mathrm{~g} / \mathrm{g})$ in polyvinyl bags and treated evenly onto the greenhouse soil $(2 \mathrm{~m}$ $x 5 \mathrm{~m}$ ) at the recommended dose levels of $6 \mathrm{~kg} / 10 \mathrm{a}$ of Bellisplus $^{\circledR}$ (Kyung Nong Co., Korea) for boscalid (a.i. $0.8 \%$ ) and pyraclostrobin (a.i. $0.25 \%$ ) and $3 \mathrm{~kg} / 10 \mathrm{a}$ of Veteran ${ }^{\circledR}$ (Dongbang Agro Co., Korea) for imidacloprid (a.i. $2.0 \%$ ) and $3 \mathrm{~kg} / 10 \mathrm{a}$ of Mospiran ${ }^{\circledR}$ (Kyung Nong Co., Korea) for acetamiprid (a.i. 1.5\%), respectively. The treated soils were then carefully mixed by using a Dongyang Techtool (Daegu, Korea) model KM WG420 agricultural farm management machine. In separate experiments, each pesticide was treated at rates two times higher than the recommended dose level. Commercial mustard green seeds 
<smiles>CC(=NN)N(C)Cc1ccc(Cl)nc1</smiles>

1<smiles>O=[N+]([O-])NC1=NCCN1Cc1ccc(Cl)nc1</smiles>

3<smiles>O=C(Nc1ccccc1-c1ccc(Cl)cc1)c1cccnc1Cl</smiles><smiles>COC(=O)N(c1ccccc1COc1ccn(-c2ccc(Cl)cc2)n1)C(C)C</smiles>

Fig. 1. Chemical structures of acetamiprid (1), boscalid (2), imidacloprid (3), and pyraclostrobin (4) examined in this study.

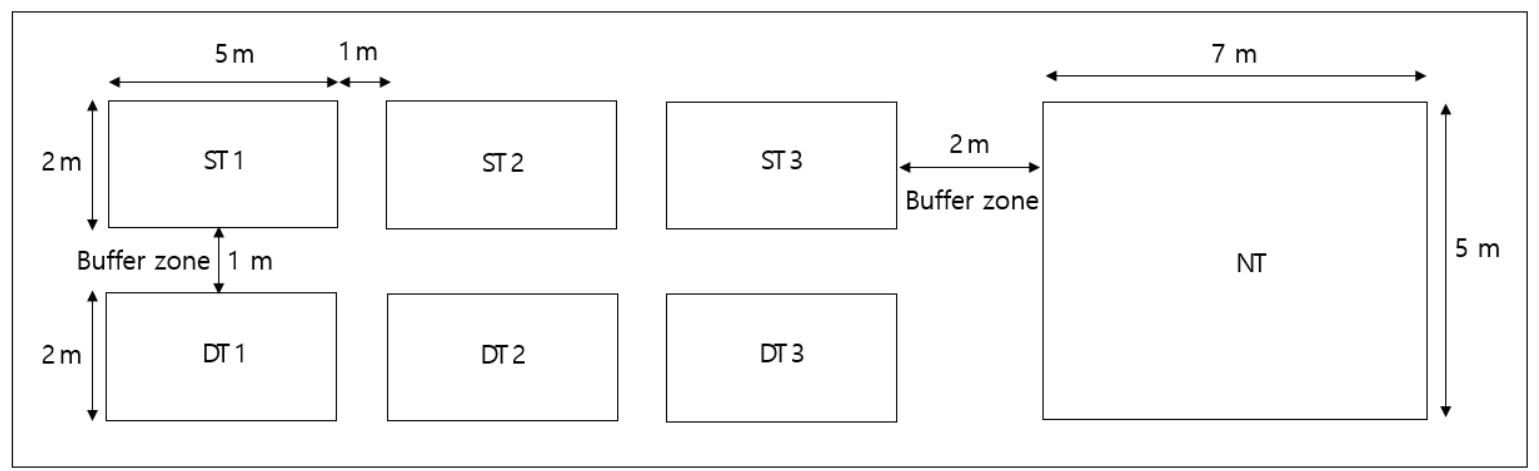

Fig. 2. Experimental design of the plots for the greenhouse experiments. ST: single dose treatment, DT: double dose treatment, NT: not treated (control).

(red leaf mustard) purchased from Nongwoo Bio (Suwon, Korea) were sown 1 day at a distance of $25 \mathrm{~cm}$ between plants after the pesticide treatment according to the manufacturer's recommendation. The experimental plots for the greenhouse experiments were designed in triplicate as presented in Fig. 2.

Mustard greens were cultivated conventionally for 53 days under greenhouse conditions. Mustard green samples were collected from the field trial greenhouse and then chopped into small pieces followed by grinding fully using a high-speed homogenizer. Soil samples were collected by using a model SL09018 stainless soil auger (Shinill Science INC., Korea) at a depth of 0-20 cm from eight points in each plot after the harvest. The soil samples were then air-dried overnight and passed through a 2-mm sieve. All samples were then stored at $-20^{\circ} \mathrm{C}$ until used.

\section{Sample Preparation}

Sample preparation for pesticide analyses in plant and soil samples were performed with methods modified from QuEChERS, as described below. The methods were optimized by modifying several factors such as extraction solvent, extraction time, centrifugation and extraction kit.

For acetamiprid, a $10 \mathrm{~g}$-sample was added with $10 \mathrm{~mL}$ of acetonitrile to a $50 \mathrm{~mL}$ centrifuge tube. The sample was vortexed vigorously for $2 \mathrm{~min}$ and mixed with 6.0 $\mathrm{g}$ of anhydrous $\mathrm{MgSO}_{4}$ and $1.5 \mathrm{~g}$ of $\mathrm{NaOAC}$ followed by vortexing again for $2 \mathrm{~min}$. The mixture was centrifuged at $4,500 \mathrm{rpm}$ for $5 \mathrm{~min}$ to obtain supernatant. A $1 \mathrm{~mL}$-aliquot of supernatant was transferred into a $2 \mathrm{~mL}$ microcentrifuge tube containing anhydrous $\mathrm{MgSO}_{4}(150 \mathrm{mg}$ ), PSA (25 mg) and GCB (2.5 mg), mixed for $2 \mathrm{~min}$ and centrifuged at 10,000 rpm for $5 \mathrm{~min}$. The resultant supernatant was used for LC/MS/MS analysis after being passed through a $0.2 \mu \mathrm{m}$ syringe membrane filter (PTFE-H).

For boscalid, a $10 \mathrm{~g}$-sample was added with $10 \mathrm{~mL}$ of acetonitrile to a $50 \mathrm{~mL}$ centrifuge tube and vortexed vigorously with $6.0 \mathrm{~g}$ of anhydrous $\mathrm{MgSO}_{4}$ and $1.5 \mathrm{~g}$ of 
$\mathrm{NaOAC}$ for $2 \mathrm{~min}$. The mixture was then vortexed for $2 \mathrm{~min}$ and centrifuged at 4,500 rpm for $5 \mathrm{~min}$. An aliquot $(1.0 \mathrm{~mL})$ of supernatant was transferred into a $2 \mathrm{~mL}$ micro-centrifuge tube and mixed with anhydrous $\mathrm{MgSO}_{4}$ (150 mg), PSA (25 mg) and GCB (2.5 mg) for $2.0 \mathrm{~min}$. The mixture was centrifuged at 10,000 rpm for $5 \mathrm{~min}$, and the resultant supernatant was used for LC/MS/MS analysis as described above.

For pyraclostrobin, a 10 g-sample was added to a 50 $\mathrm{mL}$ centrifuge tube. The sample was added with $10 \mathrm{~mL}$ of acetonitrile and mixed vigorously for 2 min together with $4.0 \mathrm{~g}$ of anhydrous $\mathrm{MgSO}_{4}, 1.0 \mathrm{~g}$ of $\mathrm{NaCl}, 1.0 \mathrm{~g}$ of trisodium citrate dehydrate and $0.5 \mathrm{~g}$ of disodium hydrogen citrate sesquihydrate. The mixture was vortexed for $2 \mathrm{~min}$ and centrifuged at 4,500 rpm for $5 \mathrm{~min}$. A $1.0 \mathrm{~mL}$-aliquot of supernatant was transferred into a $2 \mathrm{~mL}$ micro-centrifuge tube and mixed with anhydrous $\mathrm{MgSO}_{4}(150 \mathrm{mg})$, PSA (25 mg) and GCB (2.5 mg) were added to the tube. The mixture was then vortexed for $2 \mathrm{~min}$ and centrifuged at 10,000 rpm for $5 \mathrm{~min}$. The resultant supernatant was used for LC/MS/MS analysis as described above. Sample preparation for BF500-3, a pyraclostrobin metabolite, was performed as described for pyraclostrobin, except not using GCB.

Sample preparation for imidacloprid was conducted by extracting sample (10 g) with $10 \mathrm{~mL}$ of acetonitrile containing $4.0 \mathrm{~g}$ of anhydrous $\mathrm{MgSO}_{4}, 1.0 \mathrm{~g}$ of $\mathrm{NaCl}$, $1.0 \mathrm{~g}$ of trisodium citrate dehydrate and $0.5 \mathrm{~g}$ of disodium hydrogen citrate sesquihydrate in a $50 \mathrm{~mL}$ centrifuge tube for $2 \mathrm{~min}$. The extracts was centrifuged at 4,500 rpm for $5 \mathrm{~min}$, and a $1.5 \mathrm{~mL}$-aliquot of supernatant was transferred into a $2 \mathrm{~mL}$ micro-centrifuge tube containing anhydrous $\mathrm{MgSO}_{4}(150 \mathrm{mg})$, PSA (25 mg) and GCB (7.5 $\mathrm{mg}$ ). The mixture was vortexed for $2 \mathrm{~min}$ and centrifuged at 10,000 rpm for $5 \mathrm{~min}$. The resultant supernatant was used for LC/MS/MS analysis.

Chemical stability of the pesticides in the samples during storage at $-20^{\circ} \mathrm{C}$ was examined by calculating the recovery data of the standard solutions spiked in the control samples at a level of $0.1 \mathrm{mg} / \mathrm{L}$. The spiked samples were stored at $-20^{\circ} \mathrm{C}$ during the same period as the field sample storage period until analyzed.

\section{Method Validation}

Method validation was performed based on ion ratio, linearity, sensitivity, precision, and accuracy, following the guidance of European Commission document SANTE/ $11813 / 2017$. Default maximum permitted tolerances of the ion ratio was set as within $\pm 30 \%$ of relative average of calibration standards from the sequence analysis. A qualitative ion ratio was employed to indicate the presence of interferences, and it was calculated as the ratio of the peak area for the quantifier transition to the peak area of qualifier transition in calibration standard and sample matrix solutions. The selected ions used in calculating the ion ratio are presented in Table 1 . The linearity of standard solutions of the pesticides was obtained from matrix-matched calibration curve by diluting serially their stock solutions $(100 \mathrm{mg} / \mathrm{L})$ with the extracts of control samples into their working solutions ranged from $2.5 \mu \mathrm{g} / \mathrm{L}$ to $200 \mu \mathrm{g} / \mathrm{L}$. The method sensitivity was determined by the quantification of limit (LOQ) at the signal to noise of 10:1. The LOQ was calculated as: LOQ $(\mathrm{mg} / \mathrm{kg})=[$ minimum detectable amount $(\mathrm{ng}) \times$ final sample volume $(\mathrm{mL})] /[$ injection volume $(\mu \mathrm{L}) \times$ sample amount $(\mathrm{g})]$. The precision and accuracy of the method were assessed by calculating the recovery data using the standard solutions fortified in the control samples at levels of LOQ and 10LOQ. Recovery data were accepted when the values were in the range of $70-120 \%$ with the relative standard deviation (RSD) less than 20\%. Recovery was performed in triplicate, and the data were calculated as: recovery (\%) $=$ (the concentration detected in sample) / (the fortified concentration) $\times 100$. Particularly, the concentrations of pyraclostrobin in the samples were calculated as following,

Table 1. Instrument parameters for analysis of pesticides in multiple reaction mode

\begin{tabular}{cccc}
\hline \multirow{2}{*}{ Pesticide } & Precursor ions $(\mathrm{m} / \mathrm{z})$ & \multicolumn{2}{c}{ Product ion $(\mathrm{m} / \mathrm{z})$ and collision energy $(\mathrm{eV})$} \\
\cline { 3 - 4 } & & Quantitation & Qualitation \\
\hline Acetamiprid & 223.1 & $125.9(21)$ & $56.0(23)$ \\
Boscalid & 343.0 & $306.9(22)$ & $139.9(22)$ \\
Imidacloprid & 256.2 & $209.1(15)$ & $175.1(23)$ \\
Pyraclostrobin & 388.1 & $194.2(20)$ & $162.8(11)$ \\
BF500-3 & 358.1 & $326.0(16)$ & $164.0(17)$ \\
\hline
\end{tabular}




$$
\mathrm{P}=\mathrm{P}+(\mathrm{B} \times \mathrm{F})
$$

$\mathrm{P}$ : residue concentration of pyraclostrobin $(\mathrm{mg} / \mathrm{kg})$

B: residue concentration of BF500-3 (mg/ kg)

F: conversion factor, molecular weight $(\mathrm{MW})$ of pyraclostrobin / MW of BF500-3 = 387.83 / 357.80 $=1.08$

\section{Instrument}

LC/MS/MS was a Waters model Xevo TQ-XS triple quadrupole mass spectrometer equipped with a Waters model ACQUITY ${ }^{\mathrm{TM}}$ UPLC system. An Osaka Soda CAPCELL CORE C18 stainless column $(150 \times 2.1 \mathrm{~mm}$, $2.7 \mu \mathrm{m}$ thickness) was used for the chromatographic separation. The mobile phase was consisted of acetonitrile (A) and water (B) containing $0.1 \%(\mathrm{v} / \mathrm{v})$ formic acid, and its isocratic and gradient were performed as follows: for acetamiprid, isocratic 15\% solvent A for $1.0 \mathrm{~min}$, linear gradients $60 \%$ solvent $\mathrm{A}$ for $1.5 \mathrm{~min}$ and $90 \%$ solvent $\mathrm{A}$ for $10 \mathrm{~min}$, isocratic $90 \%$ solvent $\mathrm{A}$ for $10 \mathrm{~min}$, flow rate $0.3 \mathrm{~mL} / \mathrm{min}$; for boscalid, isocratic $60 \%$ solvent $\mathrm{A}$, flow rate $0.2 \mathrm{~mL} / \mathrm{min}$; for imidacloprid, isocratic $5 \%$ solvent A for $0.25 \mathrm{~min}$, linear gradient $100 \%$ solvent A for 7.75 min, isocratic $100 \%$ solvent A for $8.5 \mathrm{~min}$, flow rate 0.45 $\mathrm{mL} / \mathrm{min}$; for BF500-3 and pyraclostrobin, isocratic 50\% solvent A for $3.0 \mathrm{~min}$, linear gradient $80 \%$ solvent A for $9.0 \mathrm{~min}$, isocratic $80 \%$ solvent A for $13 \mathrm{~min}$, flow rate 0.3 $\mathrm{mL} / \mathrm{min}$. LC/MS/MS spectra were acquired with the positive ion in electron spray ionization (ESI) mode. The routine conditions of LC/MS/MS were optimized and set as de-solvation gas flow $10.8 \mathrm{~mL} / \mathrm{min}\left(\mathrm{N}_{2}\right)$, capillary gas flow $0.34 \mathrm{~mL} / \mathrm{min}$, capillary voltage $3 \mathrm{KV}$, ion source temperature $150^{\circ} \mathrm{C}$ and de-solvation temperature $350^{\circ} \mathrm{C}$.

\section{Results and Discussion}

The methods for sample preparation and LC/MS/MS parameters were validated in order to evaluate the residues of pesticides in mustard green samples obtained from field trails. The validation was examined based on the linearity, ion ratio, sensitivity, precision and accuracy, following the guidance of European Commission document SANTE/11813/2017. Table 2 shows the linear equations, coefficient values of determination $\left(r^{2}\right)$, ion ratios, and matrix effects of standard solutions. All pesticides showed $r^{2}$ values greater than 0.995 in matrix standard solution. The matrix effects were obtained from the slopes of linear relationships in between solvent only and matrix-matched calibrations, as matrix effect $(\%)=$ (slope of linearity curve in matrix - slope of linearity curve in solvent only) / slope of linearity curve in solvent only $\times 100 \%$ [12]. The matrix effects ranged from average -61.642 to $24.719 \%$, suggesting that the matrix effect should be considered for standard calibration. If the matrix effect is lower than $\pm 10 \%$, the matrix can be ignored [13]. Thus, the matrix-matched calibration was employed in this study because the effects were higher than $\pm 10 \%$. Ion ratios of the peak area for the quantifier transition to the peak area of qualifier transition for matrix solutions ranged from approximately 0.13 to 2.31 , demonstrating the

Table 2. Linear equations, coefficient values of determinations $\left(r^{2}\right)$, ion ratios and matrix effects of pesticide standard solutions

\begin{tabular}{|c|c|c|c|c|c|c|c|}
\hline Matrix & Pesticide & Linear slope equation & $r^{2}$ & Ion ratio ${ }^{1)}$ & $\begin{array}{c}\text { Matrix } \\
\text { effect }(\%)^{2)}\end{array}$ & $\begin{array}{c}\text { Ion ratio } \\
\text { tolerance }(\%)^{3)}\end{array}$ & $\begin{array}{c}\text { LOQ } \\
(\mathrm{mg} / \mathrm{kg})\end{array}$ \\
\hline \multirow{5}{*}{$\begin{array}{c}\text { Neat } \\
\text { solvent }\end{array}$} & Acetamiprid & $y=20.493 x+36.711$ & 0.9993 & 0.206 & - & - & - \\
\hline & Boscalid & $y=11.956 x-12.189$ & 0.9953 & 0.405 & - & - & - \\
\hline & Imidacloprid & $y=13.083 x+25.737$ & 0.9973 & 0.822 & - & - & - \\
\hline & Pyraclostrobin & $y=70.879 x+80.044$ & 0.9973 & 2.381 & - & - & - \\
\hline & BF500-3 & $y=143.29 x+283.71$ & 0.9994 & 0.128 & - & - & - \\
\hline \multirow{5}{*}{$\begin{array}{l}\text { Mustard } \\
\text { green }\end{array}$} & Acetamiprid & $y=7.6557 x+5.7285$ & 0.9994 & 0.242 & -62.642 & 17.476 & 0.01 \\
\hline & Boscalid & $y=12.504 x-7.8278$ & 0.9990 & 0.400 & -2.358 & -1.234 & 0.01 \\
\hline & Imidacloprid & $y=14.097 x+17.731$ & 0.9998 & 0.806 & 7.751 & -1.946 & 0.01 \\
\hline & Pyraclostrobin & $y=73.869 x+33.34$ & 0.9999 & 2.314 & 4.218 & -2.814 & 0.01 \\
\hline & BF500-3 & $y=178.71 x+496.72$ & 0.9995 & 0.129 & 24.719 & 0.781 & 0.01 \\
\hline
\end{tabular}

\footnotetext{
1) Peak area of qualitation ion/peak area of quantitation ion.

2) [(Slope of linearity curve in matrix - slope of linearity curve in solvent only)/(slope of linearity curve in solvent only)] $\times 100 \%$.

3) (Average ion ratio in sample - average ion ratio in solvent)/(average ion ratio in solvent) $x 100$.
} 
presence of target pesticides in the samples as shown in Fig. 3. Pyraclostrobin showed the highest ion ratio among the pesticides. In this study, the default maximum permitted tolerances of the ion ratio was set as within $\pm 30 \%$ during the sequence analysis, following to the guidance of the document SANTE/11813/2017. The ion ratio tolerance ranged from -2.895 to $17.476 \%$ depending on the pesticide (Table 2), finding the ratios within $\pm 30 \%$. These results reveals that the presence of the pesticides was confirmed really in the sample solutions.

Table 3 shows the data for the recovery values of the pesticides obtained from the fortified samples at LOQ and 10LOQ levels. The LOQ level was $0.01 \mathrm{mg} / \mathrm{kg}$ for all pesticides at the signal to noise of 10:1. The recovery values ranged from average 77.5 to $98.4 \%$ at LOQ level with relative standard deviation (RSD) values lower than approximately $14 \%$ while the values ranged from average 79.2 to $101.2 \%$ at 10LOQ level with RSD values lower than about $5 \%$. These precision was acceptable accuracy to the guidance of document SANTE/11813/2017. Overall, the results indicated that the methods examined in this study were validated sufficiently in terms of sensitivity, precision and accuracy, which meets the requirement for pesticide residue analysis in the program of Crop Residue Analysis of Minor Crop for Pesticide Registration Authority of Rural Development of Administration (RDA), Republic of Korea.

The methods validated above were apply for the determination of acetamiprid, boscalid, BF500-3, imidacloprid and pyraclostrobin in mustard green products cultivated under greenhouse conditions for 53 days after sown. Table 4 shows the concentrations of the target pesticides found in the samples. LC/MS/MS analyses detected the pesticide residues lower than the LOQ level $(0.01 \mathrm{mg} / \mathrm{kg})$ in the samples treated with the pesticides single and double dose levels. Particularly, pyraclostrobin was detected at the LOQ level even if the residue amount of its metabolite was combined
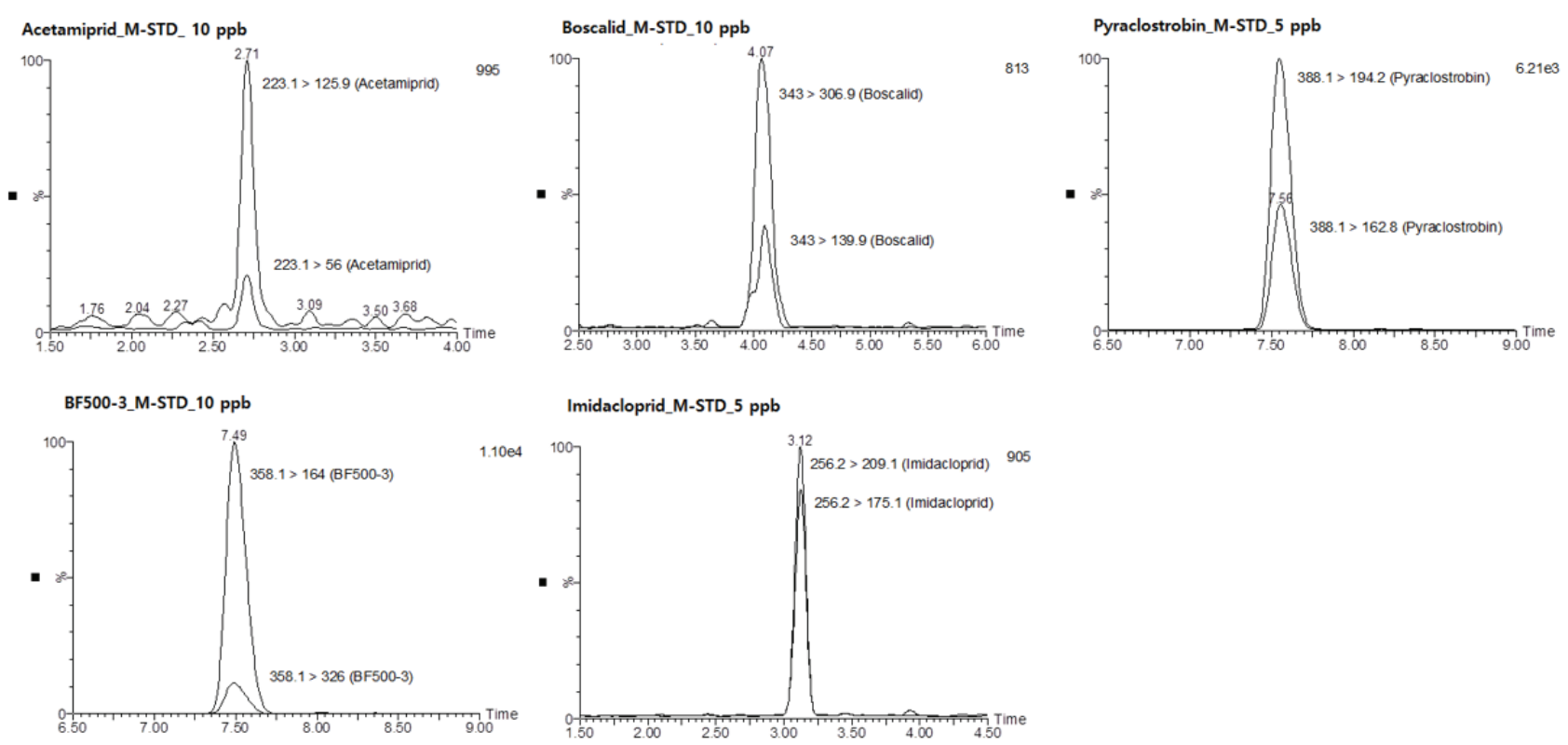

Fig. 3. Typical LC/MS/MS spectra of pesticides at minimum detectable levels examined in this study.

Table 3. Recovery values of pesticides fortified in control mustard green samples

\begin{tabular}{ccc}
\hline \multirow{2}{*}{ Pesticide } & \multicolumn{2}{c}{ Recovery values $(\%)^{*}$} \\
\cline { 2 - 3 } & 1LOQ level $(0.01 \mathrm{mg} / \mathrm{kg})$ & 10LOQ level $(0.1 \mathrm{mg} / \mathrm{kg})$ \\
\hline Acetamiprid & $88.1 \pm 12.3$ & $96.0 \pm 4.3$ \\
Boscalid & $77.5 \pm 1.1$ & $92.7 \pm 4.6$ \\
Imidacloprid & $98.4 \pm 5.6$ & $701.2 \pm 3.4$ \\
Pyraclostrobin & $81.0 \pm 2.4$ & $79.2 \pm 3.3$ \\
BF500-3 & $80.5 \pm 4.8$ & $96.7 \pm 1.1$ \\
\hline
\end{tabular}

\footnotetext{
* Means \pm SD of triplicate.
} 
Table 4. Residue concentrations of pesticides in mustard green samples cultivated under greenhouse conditions

\begin{tabular}{|c|c|c|}
\hline \multirow{2}{*}{ Pesticide } & \multicolumn{2}{|c|}{ Concentration $(\mathrm{mg} / \mathrm{kg})^{1)}$} \\
\hline & Single treatment & Dual treatment \\
\hline Acetamiprid & $<0.01$ & $<0.01$ \\
\hline Boscalid & $<0.01$ & $<0.01$ \\
\hline Imidacloprid & $<0.01$ & $<0.01$ \\
\hline Pyraclostrobin ${ }^{2)}$ & $<0.01$ & $<0.01$ \\
\hline
\end{tabular}

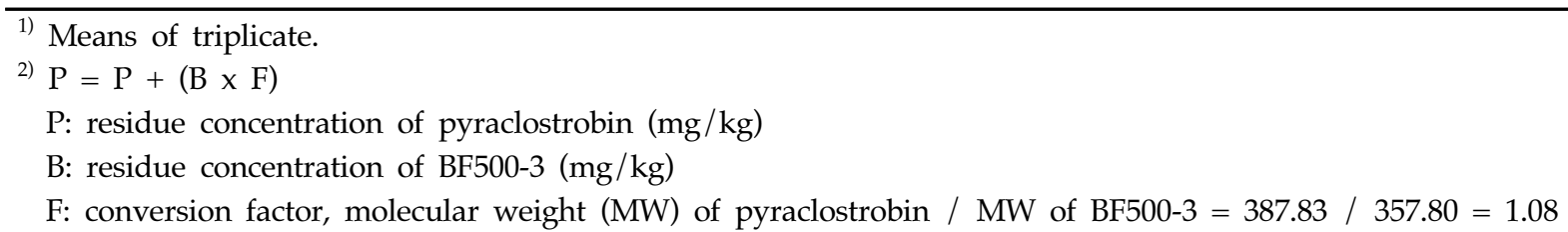

together. The pesticides were chemically stable during the experiment, which was confirmed by storage stability tests (Supplemental S1). Supplemental experiments were performed in order to investigate pesticide residues in soil samples after plant harvest. The data showed the residue levels ranged from approximately $0.01 \mathrm{mg} / \mathrm{kg}$ to $0.9 \mathrm{mg} / \mathrm{kg}$ (Supplemental S2). Although the transport ratio from the soil to the plant was not evaluated in this study, low concentration of the pesticides in the soil would result in low residue level in the plant samples. Boscalid has been reported to degrade rapidly in 28 days after treated in soil at $3.0 \mathrm{mg} / \mathrm{kg}$ and $6.0 \mathrm{mg} / \mathrm{kg}$, resulting in approximately 72 to $82 \%$ degradation of initial levels, in which the uptake ratio of boscalid from the soil to cabbage was lower than $2.4 \%$ of the initial level found in the soil [14]. European Food Safety Authority (EFSA) demonstrated that the residues of pyraclostrobin in rotational crops resulting from the soil uptake are not expected to be higher than $0.01 \mathrm{mg} / \mathrm{kg}$ [15]. In a field study of imidacloprid, the residue of imidacloprid was reported to be below the LOQ of $0.01 \mathrm{mg} / \mathrm{kg}$ in rotational crops after bare soil application [16]. A study of acetamiprid on rotational crops was suggested not to require because it is rapidly degraded in soil, giving the $90 \%$ degradation time ( $\mathrm{DT}_{90}$ ) of approximately 20 days [17]. These previous studies suggested that the pesticides tested in this study are generally degraded in a short time in agricultural products including plant and soil, contributing to the residue level of $0.01 \mathrm{mg} / \mathrm{k}$ as obtained from this study. Overall, our study suggested that acetamiprid, boscalid, imidacloprid and pyraclostrobin treated at their recommended application levels would not violate PLS since their residue levels in the plant samples were lower than $0.01 \mathrm{mg} / \mathrm{kg}$.

PLS is one of worldwide regulation guidelines against pesticide residue violation in agricultural products. The domestic and imported products containing unregistered pesticide at a level higher than $0.01 \mathrm{mg} / \mathrm{kg}$ are not allowed to sale or distribute under PLS in Korea. A number of countries belonging to OECD have performed PLS in order to control more strongly pesticide residue in agricultural product, and Korea has applied PLS to whole agricultural products since January 1, 2019. However, PLS has generated a number anxious issues for agricultural farmers who would accidently violate PLS due to unpredictable pesticide contamination through rotational crop, drift and groundwater. Particularly, the rotational crop system has a high potentiality of unpredictable pesticide contamination because the pesticide that had been used for the first crop would be taken and transported by the secondary crop. In case of the pesticides used for the first crop are not registered for the second crop and found at a level higher than $0.10 \mathrm{mg} / \mathrm{kg}$, the second crop becomes to violate PLS. Thus, much effort is required to resister pesticides available for the second crops. In this study, we examined the residues of acetamiprid, boscalid, imidacloprid and pyraclostrobin in mustard green, a typical rotational minor crop, under greenhouse conditions in order to document basic data officially required for their registration. The methods for the determination of the target pesticides in the mustard green samples were optimized to the guidance of the document SANTE/11813/2017 that is required officially by RDA for pesticide residue analysis. In conclusion, based on experimental data, the target pesticides have little potential to violate PLS in mustard green.

\section{Note}

The authors declare no conflict of interest. 


\section{Acknowledgement}

This work was financially supported by a grant from Rural Development of Administration, Republic of Korea, in the program (PJ014491) of Crop Residue Analysis of Minor Crop for Pesticide Registration Authority to Establish the Post-Harvest Interval (PHI) and Maximum Residue Limit (MRL).

\section{References}

1. Lee M (2013) Management and regulation on the minor use of pesticides in Korea and foreign countries. The Korean Journal of Pesticide Science, 17, 231-235. http://dx.doi.org/10.7585/kjps.2013.17.3.231.

2. Anastassiades M, Lehotay SJ (2003) Fast and easy multiresidue method employing acetonitrile extraction/ partitioning and dispersive solid-phase extraction for the determination of pesticide residues in produce. Journal of AOAC International, 86, 412-431. https:// doi.org/10.1093/jaoac/86.2.412.

3. Lehotay SJ, Mśstovská K, Lightfield AR (2005) Use of buffering and other means to improve results of problematic pesticides in a fast and easy method for residue analysis of fruits and vegetables. Journal of AOAC International, 88, 615-629. https:// doi.org/10.1093/jaoac/88.2.615.

4. Koesukwiwat U, Lehotay SJ, Mśstovská K, Dorweiler $\mathrm{KJ}$, Leepipatriboon $\mathrm{N}$ (2010) Extension of the QuEChERS method for pesticide residues in cereals to flaxseeds, peanuts, and doughs. Journal of Agricultural Food and Chemistry, 58, 5950-5958. https://doi.org/10.1021/jf902988b.

5. Galani JHY, Houbraken M, Wumbei A, Djeugap JF, Fotio D, Spanoghe P (2018) Evaluation of 99 pesticide residues in major agricultural products from the western highlands zone of Cameroon using QuEChERS method extraction and LC-MS/MS and GC-ECD analyses. Foods, 7, 184. https://doi:10.3390/foods7110184.

6. Melo MG, Carqueijo A, Freitas A, Barbosa J, Silva AS (2020) Modified QuEChERS extraction and HPLC-MS/MS for simultaneous determination of 155 pesticide residues in rice (Oryza sativa L.). Foods, 9, 18. https:// doi.org/10.3390/foods9010018.

7. Park J, Park Y, An J, Park S, Choi J, Koo H, Kim G (2013) Insecticidal activity of 27 insecticides to pear psylla, Cacopsylla pyricola (Foerster) (Hemiptera: Psyllidae) in Jincheon. The Korean Journal of Pesticide Science, 17, 72-75. http://dx.doi.org/10.7585/kjps.2013.17.1.72.

8. Chang T, Ryu Y, Lim H, Choi M, Jeong B, Kim C, Lee
Y (2006) Evaluation of fungicides for preventive and curative effects against powdery mildew on oriental melon. Korean Journal of Environmental Agriculture, 25, 85-92, https: / / doi.org/10.5338/KJEA.2006.25.1.085.

9. Chang S, Jung S, Kim S, Park J, Lee J (2013) Control effect on dollar spot disease caused by Sclerotinia homoeocarpa under different application rates and intervals with two mixed fungicides. Weed Turfgrass Science, 2, 408-412. https://doi.org/10.5660/WIS.2013.24.408.

10. Kim Y, Yoo J, Hong S, Lee J, Ryu G, Kim W (2017) Comparison of the three insecticides efficacy against turnip aphid (Lipaphis erysimi) and cabbage aphid (Brevicoryne brassicae) in the crucifer crops. The Korean Journal of Pesticide Science, 21, 284-288. https: / / doi.org/10.7585/kjps.2017.21.3.284.

11. Kim S, Min J, Kim HT (2019) Mycological characteristics and field fitness of Colletotrichum acutatum resistant to pyraclostrobin. The Korean Journal of Pesticide Science, 23, 231-239. https://doi.org/10.7585/kjps.2019.23.3.231.

12. Wang W, Sun $Q$ Li $Y$, Wen G, Fan J, Song W, Zhao Z, Dong M (2018) Simultaneous determination of fluoxastrobin and tebuconazole in cucumber and soil based on solid-phase extraction and LC-MS/MS Method. Food Analytical Methods, 11, 750-758.

https: / / doi.org/10.1007/s12161-017-1044-6.

13. Dong M, Nie D, Tang H, Rao Q Qu M, Wang W, Han L, Song W, Han Z (2015) Analysis of amicarbazone and its two metabolites in grains and soybeans by liquid chromatography with tandem mass spectrometry. Journal of Separation Science, 38, 2245-2252.

https:// doi.org/10.1002/jssc.201500265.

14. Jeon S, Hwang J, Lee S, Kim J (2014) Uptake of boscalid and chlorfenapyr residues in soil into Korean cabbage. The Korean Journal of Pesticide Science, 18, 314-310. https: / / doi.org/10.7585/kjps.2014.18.4.314.

15. European Food Safety Authority (2017) Reasoned opinion on the modification of the existing residue levels for pyraclostrobin in varous crops. EFSA Journal, 15, 4686, 19 pp. https://doi.org/10.2903/j.efsa.2017.4686.

16. European Food Safety Authority (2019) Review of the existing maximum residue levels for imidacloprid according to Article 12 of regulation (EC) No 396/ 2005. EFSA Journal, 17, 5570, 108 pp. https: / / doi.org/10.2903/j.efsa.2019.5570.

17. European Food Safety Authority (2011) Review of the existing maximum residue levels for acetamiprid according to Article 12 of regulation (EC) No 396/2005. EFSA Journal, 9, 2328, 59 pp. https:// doi.org/10.2903/j.efsa.2011.2328. 